\title{
Diurnal and seasonal cycles of ozone precursors observed from continuous measurement at an urban site in Taiwan ${ }^{\text {ts }}$
}

\author{
Kuang-Ling Yang ${ }^{\mathrm{a}}$, Chien-Chung Ting ${ }^{\mathrm{a}}$, Jia-Lin Wang ${ }^{\mathrm{a}, *}$, \\ Oliver W. Wingenter ${ }^{\mathrm{b}}$, Chang-Chuan Chan ${ }^{\mathrm{c}}$ \\ a Department of Chemistry, National Central University, Chungli 320, Taiwan \\ ${ }^{\mathrm{b}}$ Department of Chemistry, New Mexico Institute of Mining and Technology, Socorro, NM 87001, USA \\ ${ }^{\mathrm{c}}$ Institute of Occupational Medicine and Industrial Hygiene, National Taiwan University College of Public Health, Taipei 100, Taiwan
}

Received in revised form 21 September 2004

\begin{abstract}
Hourly measurement of 56 ozone precursors was conducted by a monitoring station located in a metropolitan area in central Taiwan. After nearly a year of continuous operation at this urban site, both diurnal and seasonal cycles of nonmethane hydrocarbons (NMHCs) were clearly observed, which were caused by the interplay between source, chemical loss, and meteorology. Selected species representing three different types of major sources, namely, the household fuel leakage, vehicular exhaust and gasoline evaporation, as well as biogenic emissions exhibit dramatic diurnal or seasonal cycles with each displaying its own unique characteristics.

Ethane and propane, largely originated from leakage of natural gas or liquefied petroleum gases (LPG), showed concentrations elevating throughout the night and early morning, but began to decrease toward noon as the nocturnal temperature inversion elevated. Because of the lower chemical reactivity and somewhat more constant emissions than other measured target compounds, their diurnal cycles were presumably the direct reflection of the mixing height over the metropolitan area.

For compounds originating from vehicular plus evaporative emissions such as benzene, which accounts for most of the monitored compounds, their diurnal cycles were also largely controlled by the variation in the height of temperature inversion.

Of all the 56 species monitored, isoprene, an abundant biogenic species largely released by plants, showed distinct diurnal and seasonal cycles different from the other measured NMHCs. Its concentration usually peaked at noon in summer and fell when temperature and solar radiation reached their maximum levels, demonstrating the close relationship of isoprene with photosynthesis.

Seasonal variation was also clearly observed for the other NMHCs quantified. With the exception of isoprene, most species show higher average concentration in winter and lower average concentration in summer with the fall values being the intermediate, which presumably is caused by both the seasonal variation in HO abundance and the height of the temperature inversion.
\end{abstract}

(C) 2004 Elsevier Ltd. All rights reserved.

Keywords: Volatile organic compounds (VOCs); Non-methane hydrocarbons (NMHCs); Liquefied petroleum gases (LPG); Temperature inversion

\footnotetext{
This paper is dedicated to Professor Kwang-Ting Liu on the occasion of his 65th birthday.

*Corresponding author.
} 


\section{Introduction}

Air pollution of high surface ozone arising from photochemical formation and accumulation has plagued many regions worldwide (Grennfelt and Schjoldager, 1984; Voltz and Kley, 1988). In the presence of volatile organic compounds (VOCs) and nitrogen oxides $\left(\mathrm{NO}+\mathrm{NO}_{2}=\mathrm{NO}_{x}\right)$, ozone is photochemically produced and can accumulate to hazardous levels in certain weather conditions (Davidson, 1993; Wakamatsu et al., 1996). In order to reduce ambient ozone concentrations, anthropogenic VOC emissions, which predominantly consist of non-methane hydrocarbons (NMHCs), have been the subject of extensive control programs in many countries. Accurate characterization of ozone precursors is extremely important for understanding tropospheric ozone formation and crafting effective control strategies to better address ozone air quality management issues. In accordance with the 1990 Clean Air Act Amendments [Section 182 (C) (1)], US EPA developed rules for the initiation of Photochemical Assessment Monitoring Stations (PAMS) located in ozone non-attainment areas targeting 56 NMHCs (EPA, 1994). Given the high complexity and low abundance nature associated with ambient NMHCs, the chromatographic methods are preferred for their efficient separation and detection ability over other analytical means (Maeda et al., 1995; Oliver et al., 1996; Dewulf and Langenhove, 1999; Helmig, 1999).

To investigate the high ozone problems in Taiwan, a project has recently been undertaken in a metropolitan area (Taichung) in central Taiwan with a population over 200 million in an attempt to identify the source characteristics of ozone precursors in the source area. As a result, an auto-GC was used in Taichung city as the first step toward ultimately establishing a network of three monitoring stations in central Taiwan, where seasonal high ozone is often found in the downwind areas several tens of kilometers southeast of Taichung metropolitan area. Concurrent monitoring of selected NMHCs of $\mathrm{C}_{2}$ to $\mathrm{C}_{12}$ at the station is expected to provide the necessary abundance information and associated variation characteristics in this metropolitan area as the first step toward unraveling photochemistry that leads to high ozone formation in the downwind areas. These species were so selected either due to their relatively high photochemical activity or large abundance in ambient air. It is suspected that the ozone precursors of high concentrations are injected from the ground in the city and swept by prevailing winds to the downwind suburban areas forming ozone along the transport route. This urban monitoring station was placed in the middle of Taichung city to obtain a year's worth of hourly NMHC data consisting of 56 $\mathrm{C}_{2}-\mathrm{C}_{12}$ NMHCs, before the other two downwind stations become fully tested and functional. After more than a year of continuous monitoring at this urban site, distinct diurnal and seasonal cycles of NMHCs were observed, which is believed to be the coupling between their chemical activities, source characteristics, and the modulation by meteorology. The objective of this work is to display the unique diurnal and seasonal cycles of some typical ozone precursors and provide plausible explanation for the concentration variation based on high-quality hourly monitoring of numerous NMHCs representing a typical urban environment.

\section{Experimental}

\subsection{Monitoring site description}

This photochemical assessment monitoring station in central Taiwan is the first station ever built on the island with an aim to target high ozone events frequently occurring in spring and fall, see Fig. 1 for the satellite picture showing the torrential features of the studied area. This station is located at the center of a metropolitan area (Taichung) with population over 2 million. To avoid direct contamination by direct point sources, the station is placed in a public park where major roads and buildings are several tens to hundred meters away. Still, traffic and household emissions are believed to be the dominant source influencing the station, which is typical and representative of an urban site. Because the station sits in a park, plants are also an important source of VOCs.

\subsection{Instrumental condition}

A commercial auto-GC system (Perkin-Elmer, USA) was employed in the monitoring stations to provide unattended hourly measurement. In this system a cryogen-free sorbent trap with dual columns and dual flame ionization detectors (FIDs) were configured to cope with the wide volatility range of the components by employing one column for the lower boiling compounds and the other for the higher boiling ones. To increase the breakthrough volume of the extremely volatile species such as the $\mathrm{C}_{2}$ and $\mathrm{C}_{3}$ species such as ethane, ethene, ethyne and propane, the system used a Peltier electrical cooling device to cool the trap to $-30^{\circ} \mathrm{C}$. For each hourly analysis air is drawn via the air inlet on the roof about $5 \mathrm{~m}$ above the surface into the trap for $45 \mathrm{~min}$ with a flow rate of $20 \mathrm{~mL} \mathrm{~min}^{-1}$ set by the mass flow controller, while the previous sample is being analyzed with the GC. Excess water vapor is removed by the Nafion dryer. Upon injection, the trap is rapidly heated up to $250{ }^{\circ} \mathrm{C}$ to desorb compounds into the DB-1 column $(60 \mathrm{~m} \times 0.25 \mathrm{~mm} ; \mathrm{df}=1.0 \mathrm{~m}, \mathrm{~J} \& \mathrm{~W}$ Scientific, Folsom, CA, USA). The system was equipped with a 

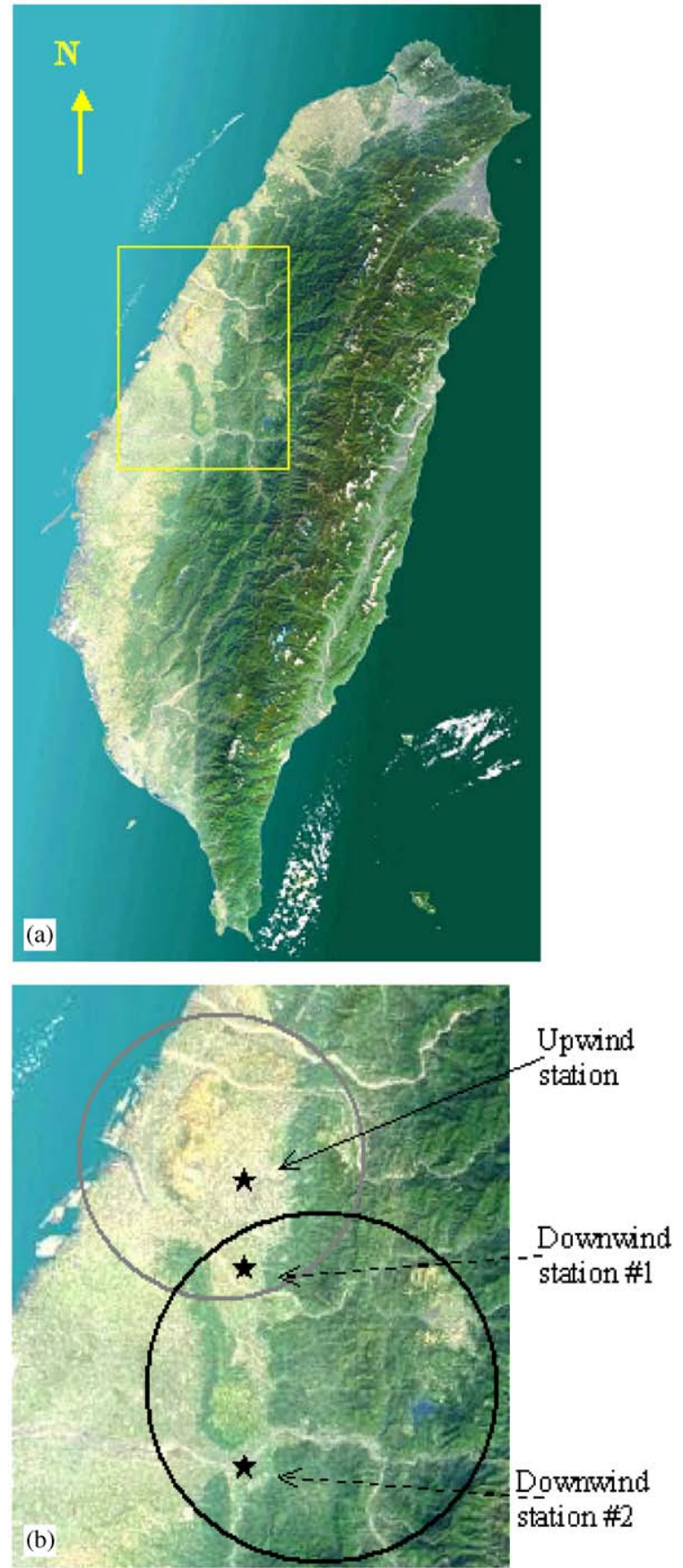

Fig. 1. (a) Satellite mapping of Taiwan. The rectangle is the studied area of central Taiwan which is enlarged below for showing the locations of the photochemical assessment monitoring stations. Mountainous areas are highlighted in darker green and the plain terrain is in lighter green. (b) The enlarged area in (a) shows the deployment of the three stations in central Taiwan. The gray circle encompasses the highly populated and urbanized area, whereas the dark circle indicates the area which is subjected to seasonal high ozone. Solid arrow indicates the site for the first monitoring station installed in
Dean's switch to heart-cut the early eluting VOCs of $\mathrm{C}_{2}-\mathrm{C}_{5}$ species from the DB-1 column, which does not provide sufficient retention for these highly volatile species, to the PLOT column $(30 \mathrm{~m} ; 0.25 \mathrm{~mm}$; df $=8 \mathrm{~m}$, Hewlett-Packard, San Fernando, CA, USA) for separating the $26 \mathrm{C}_{2}-\mathrm{C}_{5}$ compounds which are then detected by a FID. As soon as isoprene is eluted from the PLOT column the flow is then switched back to an uncoated column to elute the remaining $30 \mathrm{C}_{6}-\mathrm{C}_{12}$ compounds which can be well separated by the DB-1 column and finally into the second FID. Another advantage of the heart-cutting technique is to prevent the high boiling compounds from ever entering the PLOT column since it is prone to their interferences due to excessive retention.

\subsection{Aspects on data quality control}

Species confirmation and concentration calibration were carried out by a standard gas mixture pressurized to $1500 \mathrm{psi}$ in a cylinder containing 56 target compounds with absolute concentration ranging from 20 to $40 \mathrm{ppb} C$ (ppb multiplied by carbon number) prepared by gravimetric method (Spectra gases, Branchburg, NJ, USA) [Spectra gases website]. As a result, the hourly measurement within a day comprised 23 ambient sample injections plus one standard gas injection. Each day the retention times of the 56 compounds were updated in the method file which was used to batch the remaining 23 sample files for species identification. The system's performance was checked on a daily basis based on the drift in retention times and responses of selected compounds in the standard gas injection. As soon as a month's worth of data had been accumulated, procedures of data quality control and assurance were followed to correct errors in species identification and quantification.

Concentration calibration exploited a unique property of FID, i.e., its signal strength is proportional to the carbon number on per molecule basis (Scanlon et al., 1985). Based on numerous aliquots of the standard gas, the response factors for the 56 compounds were calculated based on the per carbon response factor of propane and benzene analyzed with the PLOT and DB-1 column, respectively. Subsequently, hourly data of the 56 compounds in the samples were calculated from this set of response factors, which were then used in the interpretation of the seasonal and diurnal variations.

Fig. 1 (continued)

2000. Dashed arrows indicate the two downwind sites, which will not be discussed in this work. The linear distance between the upwind station and the $¥ 2$ station is about $40 \mathrm{~km}$. Results and discussion in this work are only based on the observation from the first site. 
Other than performing routine quality control and assurance check on the system and the data, the performance of the system was validated by comparing the responses to an auto-GC built in our laboratory with several differences in the design and construction (Wang and Din, 2003). For instance, in the self-built system two sorbent traps were used rather than one as in the PE system, and the desorption profile for each trap was optimized for the individual column. The self-built system was placed in the station side-by-side with the PE system sharing a common air-inlet during a month long inter-system comparison experiment with excellent agreement between the two systems (Wang and Din, 2003). Because the PAM station was placed next to a regular air quality monitoring station measuring $\mathrm{CO}$, $\mathrm{O}_{3}, \mathrm{SO}_{2}, \mathrm{NO}_{x}$, etc. [EPA Taiwan website], the correlations between certain VOCs and $\mathrm{CO}$ or $\mathrm{NO}_{x}$, which are also primary pollutants in urban environment, can facilitate validating the VOC measurement (Wang and Chen, 2002).

\section{Results and discussion}

Distinct diurnal and seasonal concentration variations were observed for almost all the monitored species from the hourly measurement made in the period between February and December 2001, which consists of nearly 7000 sample injections with 56 NMHCs quantified for each injection. Although the number of monitored species is large, three major types of sources are considered to account for a large fraction of the VOC composition and concentrations, which include fuel leakage from natural gas or liquefied petroleum gases (LPG), vehicular or fuel evaporative emissions, and biological emissions. Herein, we use four species, i.e., ethane, propane, benzene, and isoprene, characteristic of each own source type for illustrating their unique diurnal and seasonal cycles. Other species of the same category exhibit similar concentration variation, and hence will not be discussed to avoid redundancy. Fig. 2 demonstrates the in-situ measurement for the four representative species to show the resolution and variation patterns with the monthly data. The systematic on-site time-series observation of NMHCs complements the more conventional canister sampling method which often emphasizes large area coverage or randomness by allowing continuous tracking of the rapid change in atmospheric concentrations. It is found that benzene and $m, p$-xylenes in Figs. 2(a) and (b) displaying similar patterns with $R^{2}=0.84$ belong to the source of car exhaust or gasoline evaporation, whereas ethane and propane in Figs. 2(c) and (d) with $R^{2}=0.81$ are likely to be emitted from the same source, namely, natural gas and LPG. The pattern of isoprene in February (Fig. 2e), however, correlates better with benzene and xylenes
$\left(R^{2}=0.51\right.$ and 0.58 , respectively) than with propane and ethane $\left(R^{2}=0.21\right.$ and 0.15 , respectively) in February, suggesting that it is mostly of vehicular origin in this particular season. Nevertheless, the correlation does not hold in hot seasons as the dominant source gradually shifts from vehicular to biogenic with concentrations peaking regularly at noon, see Fig. 2(f). In this case, there is no correlation at all for isoprene vs. benzene in August $\left(R^{2}=0.00\right)$.

The year-round hourly concentrations were statistically transformed into hourly averages and monthly distributions to better illustrate the diurnal and seasonal effects associated with the three types of sources (see discussion below).

Fuel leakage from LPG or natural gas contributes significantly to the ambient abundance of methane, ethane, propane in an urban environment, and a significant fraction of butanes in urban environment (Blake and Rowland, 1995; Chang et al., 2001). Other industrial and traffic-related sources emit negligible amounts of methane, ethane, and propane compared to the fuel leakage (McLaren and Singleton, 1996; Sagebiel et al., 1996; Chang et al., 2003). Emissions of these sources tend to be more constant and lack diurnal features compared to sources such as vehicular exhaust, or seasonal features such as evaporative or biogenic emissions (DeLuchi, 1993; Kirchstetter et al., 1999). Furthermore, the lifetimes of these three alkanes are longer than other species such as alkenes and aromatic compounds (see Table 1 for some of the measured species and their average atmospheric lifetimes relative to a $\mathrm{HO}$ concentration of $1 \times 10^{6} \# \mathrm{~cm}^{-3}$ ). As a result, chemical reaction with $\mathrm{HO}$ radicals for these three species is negligible compared to their residence time, and therefore exerts little removal force to alter their abundance in the Taichung Metropolitan Area. Because the instrument did not quantify the mixing ratio of methane, the measurements of ethane or propane were used instead to illustrate the diurnal and seasonal profiles for fuel leakage type of sources in this work. Because of the low reactivity of ethane and propane, its chemical loss can be neglected. This, along with the relatively constant emissions, greatly simplifies the interpretation of their diurnal cycles and leaves the meteorology to be the only important factor controlling the diurnal cycles of ethane and propane. The meteorological effect of nocturnal inversion caused by radiational cooling is thought to be the dominant force to modulate the concentrations of long-lived species (Wang et al., 2001). The rapid radiation of heat from the ground at night and early morning develops a temperature inversion near the surface enhancing the concentration of gaseous pollutants near the ground. The inversion top elevates and finally breaks up as the sunlight continues to heat up the surface around noon, which allows clean air to dilute these gases to its 
minimum level in a diurnal cycle. Figs. 3 and 4 show concentration variation for ethane and propane. Diurnal and seasonal variations were illustrated by the hourly averages for three different months, i.e., February, August, and October 2000, representing three different seasons, i.e., winter, summer, and fall, for illustrating the
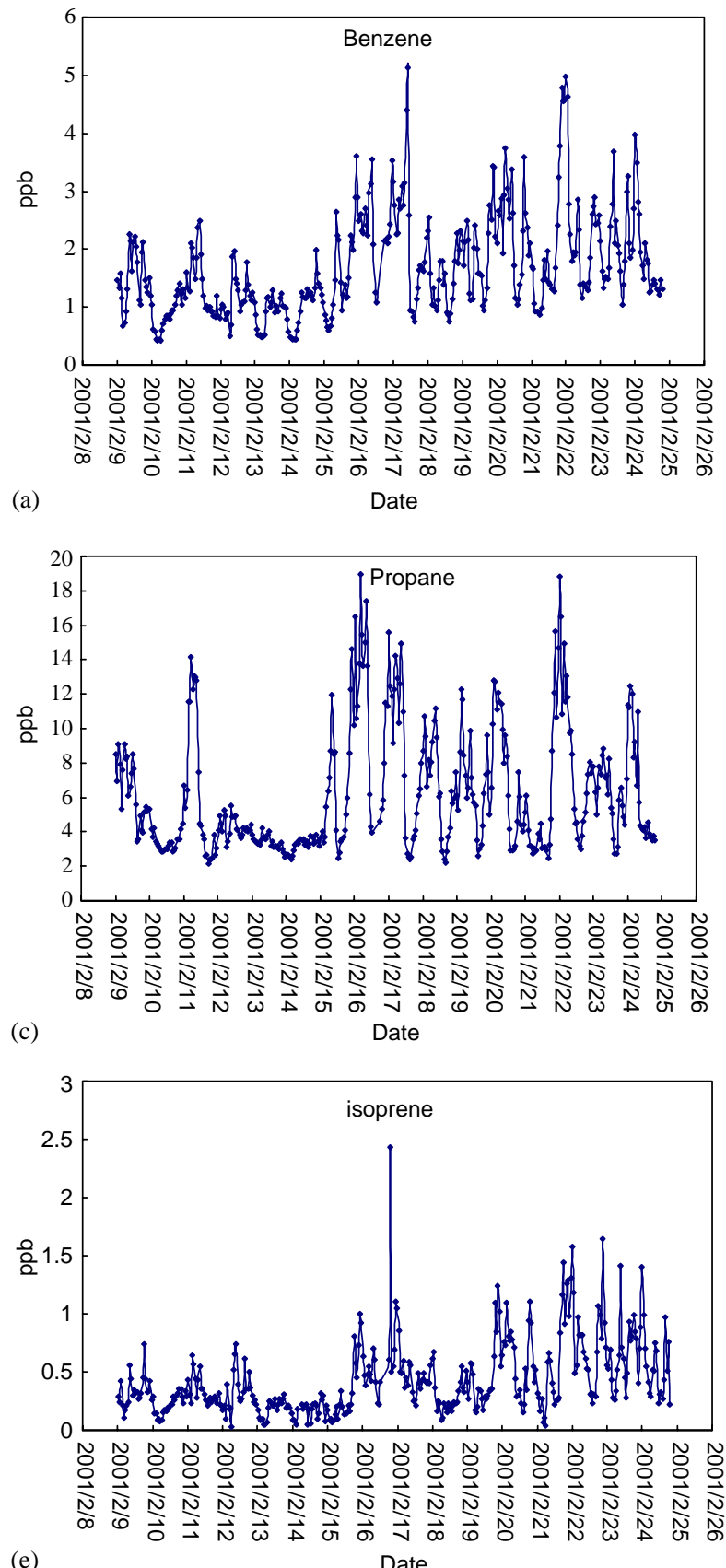

(e) effect of such temperature inversion, see Figs. 3a and 4a. Because the temperature inversion has a strong seasonality, it is usually much weaker in summer and becomes stronger toward winter. As a result, ethane or propane's mixing ratios exhibited a much larger variation in winter than in summer, see Figs. $3 \mathrm{~b}$ and $4 \mathrm{~b}$.
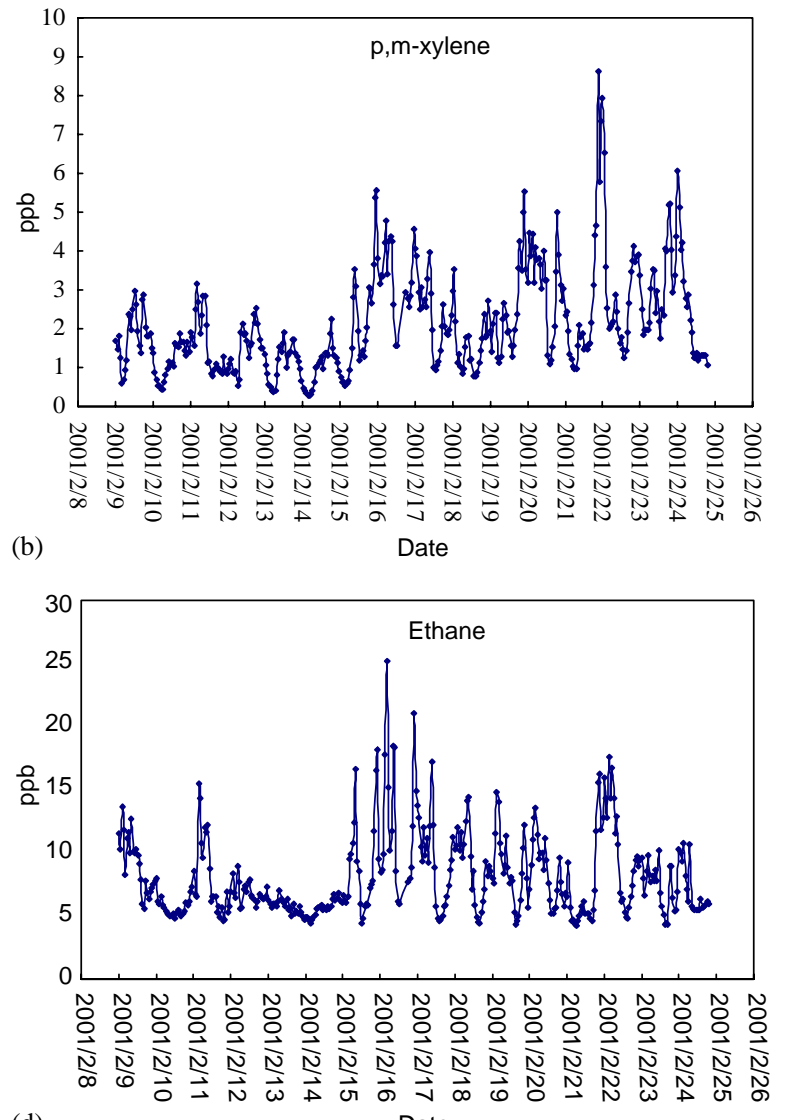

(d) Date

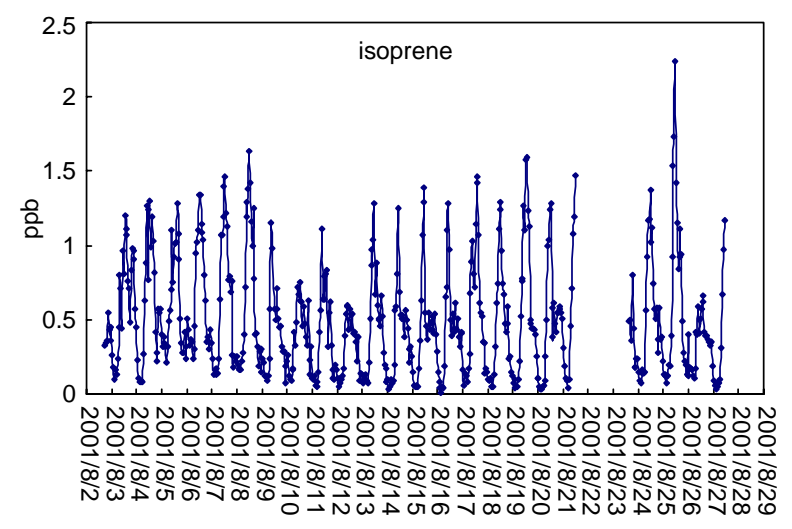

(f)

Fig. 2. On-site hourly measurement in February and August 2001 for four selected NMHCs representative of three different emission sources. (a) Benzene in February; (b) $m$, p-xylene in February; (c) propane in February; (d) ethane in February; (e) isoprene in February; (f) isoprene in August. 
Table 1

Rate constants $k_{\mathrm{OH}}$ and lifetimes at $298 \mathrm{~K}$ and 760 Torr for selected organic compounds

\begin{tabular}{|c|c|c|}
\hline \multirow[t]{2}{*}{ Compounds } & \multicolumn{2}{|l|}{$10^{12} \times k$} \\
\hline & $\left(\mathrm{cm}^{3}\right.$ molecule $\left.{ }^{-1} \mathrm{~s}^{-1}\right)$ & Tropospheric lifetime \\
\hline \multicolumn{3}{|l|}{ Alkanes } \\
\hline $\mathrm{CH}_{4}{ }^{\mathrm{a}}$ & 0.0063 & 1800 days \\
\hline $\mathrm{C}_{2} \mathrm{H}_{6}{ }^{\mathrm{a}}$ & 0.24 & 48 days \\
\hline $\mathrm{C}_{3} \mathrm{H}_{8}{ }^{\mathrm{a}}$ & 1.0 & 11 days \\
\hline$n-\mathrm{C}_{4} \mathrm{H}_{10}{ }^{\mathrm{b}}$ & 2.3 & 4.6 days \\
\hline$n-\mathrm{C}_{5} \mathrm{H}_{12}{ }^{\mathrm{c}}$ & 3.94 & 2.9 days \\
\hline$n-\mathrm{C}_{6} \mathrm{H}_{14}{ }^{\mathrm{c}}$ & 5.61 & 2.1 days \\
\hline$n-\mathrm{C}_{7} \mathrm{H}_{16}{ }^{\mathrm{c}}$ & 7.15 & 1.6 days \\
\hline \multicolumn{3}{|l|}{ Alkenes } \\
\hline $\mathrm{C}_{2} \mathrm{H}_{4}{ }^{\mathrm{a}}$ & 5.3 & 2.2 days \\
\hline $\mathrm{C}_{3} \mathrm{H}_{6}{ }^{\mathrm{b}}$ & 18 & $15 \mathrm{~h}$ \\
\hline $1-\mathrm{C}_{4} \mathrm{H}_{8}{ }^{\mathrm{c}}$ & 31 & $8.9 \mathrm{~h}$ \\
\hline$c i s-2-\mathrm{C}_{4} \mathrm{H}_{8}{ }^{\mathrm{c}}$ & 56 & $5.0 \mathrm{~h}$ \\
\hline trans $-2-\mathrm{C}_{4} \mathrm{H}_{8}{ }^{\mathrm{c}}$ & 64 & $4.3 \mathrm{~h}$ \\
\hline 1-Pentene ${ }^{\mathrm{c}}$ & 31 & $9.0 \mathrm{~h}$ \\
\hline 1-Hexene ${ }^{c}$ & 37 & $7.5 \mathrm{~h}$ \\
\hline \multicolumn{3}{|l|}{ Biogenic } \\
\hline Isoprene $^{\mathrm{b}}$ & 100 & $2.8 \mathrm{~h}$ \\
\hline$\alpha$-Pinene ${ }^{c}$ & 54 & $5.1 \mathrm{~h}$ \\
\hline$\beta$-Pinene ${ }^{c}$ & 79 & $3.5 \mathrm{~h}$ \\
\hline \multicolumn{3}{|l|}{ Alkynes } \\
\hline $\mathrm{C}_{2} \mathrm{H}_{2}{ }^{\mathrm{c}}$ & 0.78 & 15 days \\
\hline \multicolumn{3}{|l|}{ Aromatics } \\
\hline Benzene $^{c}$ & 1.2 & 9.6 days \\
\hline Toluene $^{c}$ & 6 & 1.9 days \\
\hline$o$-Xylene & 14 & $20 \mathrm{~h}$ \\
\hline$m$-Xylene & 24 & $12 \mathrm{~h}$ \\
\hline p-Xylene & 14 & $20 \mathrm{~h}$ \\
\hline Ethylbenzene & 7.1 & 1.6 days \\
\hline
\end{tabular}

${ }^{\text {a }}$ Sander et al. (2002).

${ }^{\mathrm{b}}$ http://www.iupac-kinetic.ch.cam.ac.uk/.

${ }^{\mathrm{c}}$ From Atkinson (1994).

${ }^{\mathrm{d}}$ Globally averaged $\mathrm{OH}$ concentration of $1.0 \times 10^{6}$ molecules $\mathrm{cm}^{-3}$ estimated by Prinn et al. (2001).

Other than the modulation by the mixing height, chemical removal could also add to the depth of a seasonal cycle. The average atmospheric lifetimes of ethane and propane exceed 2 months and 11 days (Table 1) based on a seasonally and globally averaged tropospheric hydroxyl concentration of about $1 \times 10^{6} \# \mathrm{~cm}^{-3}$ (Prinn, et al., 2001), which is sufficiently long enough for gaseous pollutants to homogeneously mix over the city without significant chemical loss. As a result, the daily concentration variation is mainly controlled by ventilation, instead of the chemical reactions due to HO radicals. Nevertheless, chemical reaction with $\mathrm{HO}$ radicals should not be ignored when the time
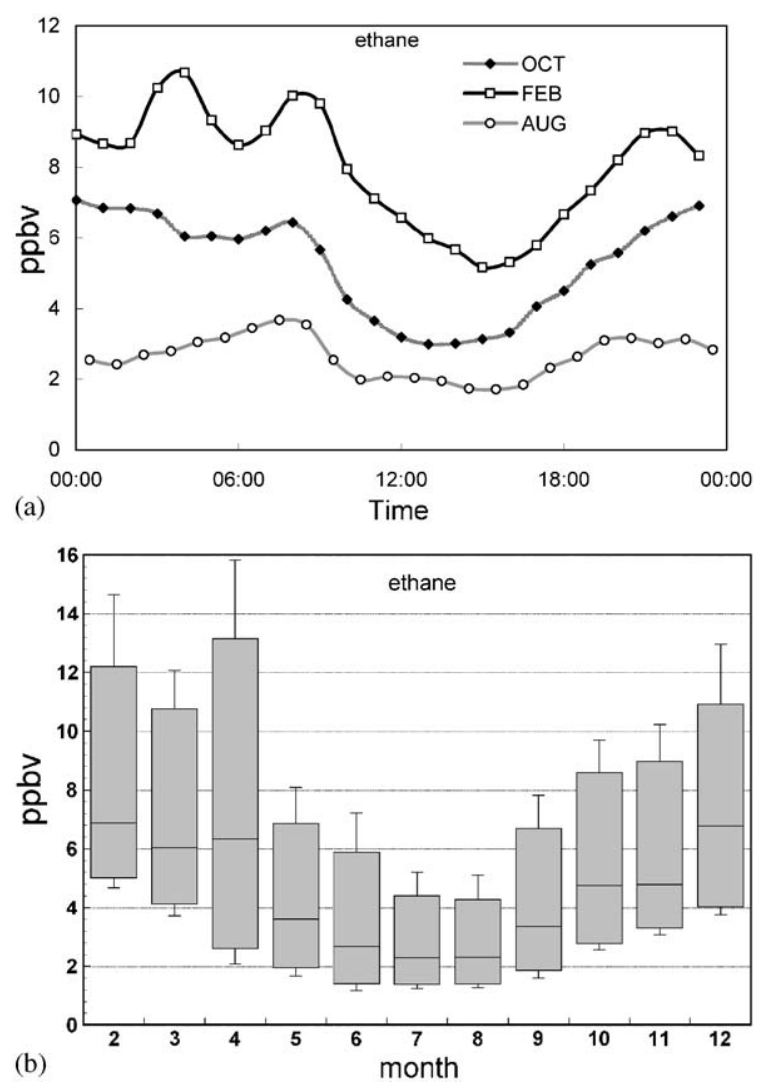

Fig. 3. (a) Hourly averaged mixing ratios of ethane in three different months for displaying both diurnal and seasonal characteristics. (b) Box-Whisker plot of ethane to display its concentration distribution in different months. The whiskers indicate the outlying 5 percentiles, whereas the boxes cover $10-90$ percentiles.

period of observation extends from a day to months, which to some degree helps shaping seasonal cycles for ethane and propane in addition to the temperature inversion.

Seasonal cycles for propane and ethane as well as for other trace gases such as $\mathrm{CO}, \mathrm{CH}_{3} \mathrm{Br}, \mathrm{CHCl}=\mathrm{CCl}_{2}$, $\mathrm{CCl}_{2}=\mathrm{CCl}_{2}$ with reasonably long lifetimes have been observed with distinct seasonal variation in background atmosphere. In those background environments inversion or change in mixing height plays little role in shaping their diurnal or seasonal cycles as their atmospheric concentrations are homogeneous and the sources are remote. In these cases, the interplay between $\mathrm{HO}$ level and the trace gases is the dominant factor that controls the seasonal variation of these species. Because $\mathrm{HO}$ atmospheric abundance has its own characteristic seasonal cycle with maximum values in summer when both solar intensity and humidity peak during a year, the trace gases show an opposite seasonal pattern to that 

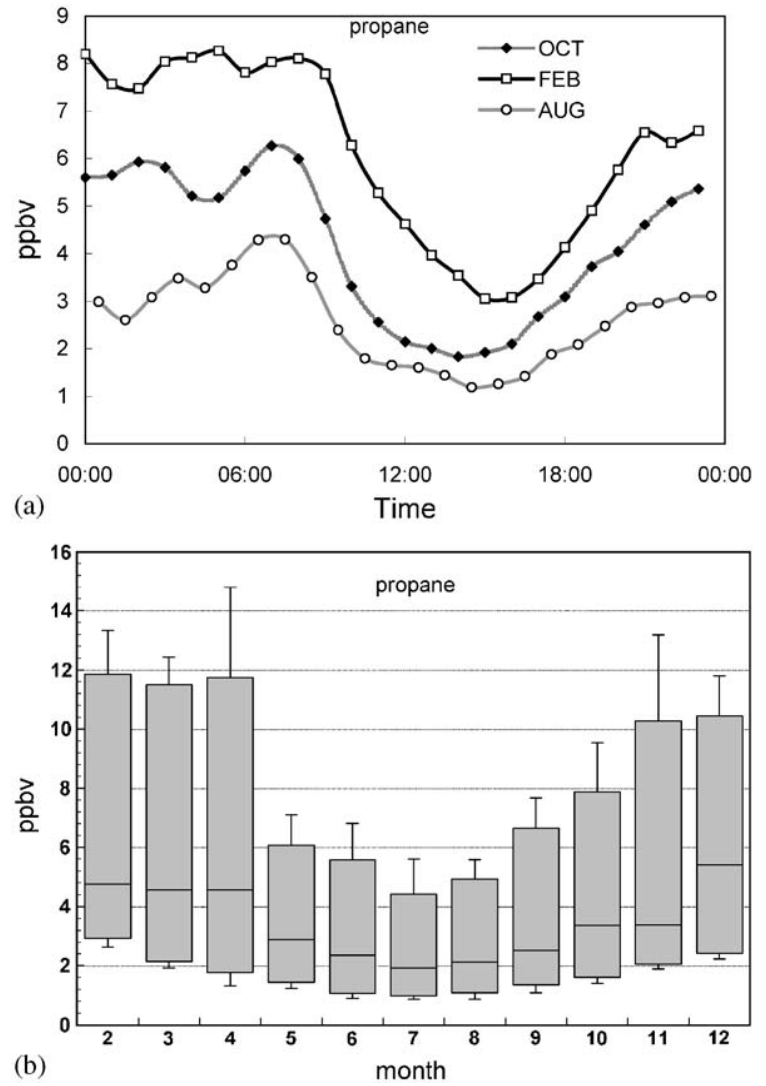

Fig. 4. (a) Same as Fig. 3a but for propane. (b) Same as Fig. 3b but for propane.

of HO radicals (Blake and Rowland, 1986; Koppmann et al., 1993; Wang et al., 1995; Novelli et al., 1998; Wingenter et al., 1998; Blake et al., 1999; NOAA/ CMDL, 2002).

The majority of the 56 NMHCs measured at the monitoring station are categorized as traffic-related species released from either vehicular or evaporative emissions or a mixture of both. The vehicles seen in this city are representative of other cities on this island, which mainly consist of passenger cars, light trucks, and two/four-stroke motorcycles. Urban ambient NMHCs mainly consist of alkanes, alkenes, and aromatics with the exception of ethane, propane, and part of $n$ - and isobutanes which originate from LPG leakage (Blake and Rowland, 1995; Wang et al., 2000). Studies have shown that urban ambient NMHCs are mostly contributed by vehicular exhaust or evaporative emissions (DeLuchi, 1993; Kirchstetter et al., 1999). Of all the 56 monitored species aromatics except toluene, such as benzene, ethylbenzene, xylenes, etc. are usually suitable for indicating traffic sources because of their high chemical stability and the lack of input other than from traffic. Unlike ethane or propane whose emissions are usually
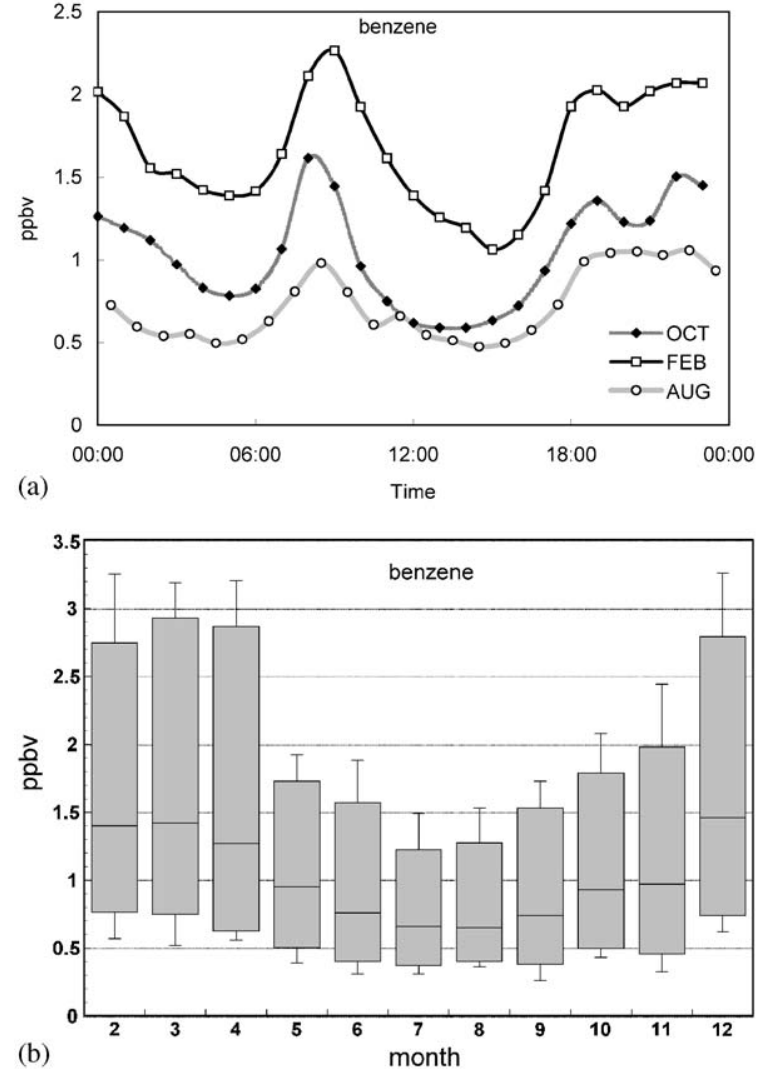

Fig. 5. (a) Same as Fig. 3a but for benzene. (b) Same as Fig. 3b but for benzene.

more ubiquitous, the presence of aromatics in the air is more variable and directly linked to the roads and traffic; see Fig. 5 for benzene's diurnal and seasonal variation. Although the mixing height also affects benzene's diurnal and seasonal profiles, the vehicular emissions, which peak in the morning around 7-8 AM and in the evening after $6 \mathrm{PM}$, enhanced the amplitude of benzene's diurnal profile (Fig. 5a). Similar to propane, benzene's mixing ratios vary more in winter than in summer possibly due to the more pronounced nocturnal radiational cooling effect (Fig. 5b).

Assuming that the mixing conditions were the same for all VOCs, the fact that benzene's diurnal pattern appears to be more dramatic than that of propane manifests the difference in the emission patterns. Consequently, it is compelling to use ethane or propane to serve as a reference species to deconvolute the diurnal or seasonal cycles induced by both emissions and meteorology for other VOCs whose emissions exhibit more variable diurnal or seasonal features. In Fig. 6 when benzene's yearly data were divided by propane's data to cancel out the meteorological modulation on concentration, a very different pattern from Fig. 5b was 


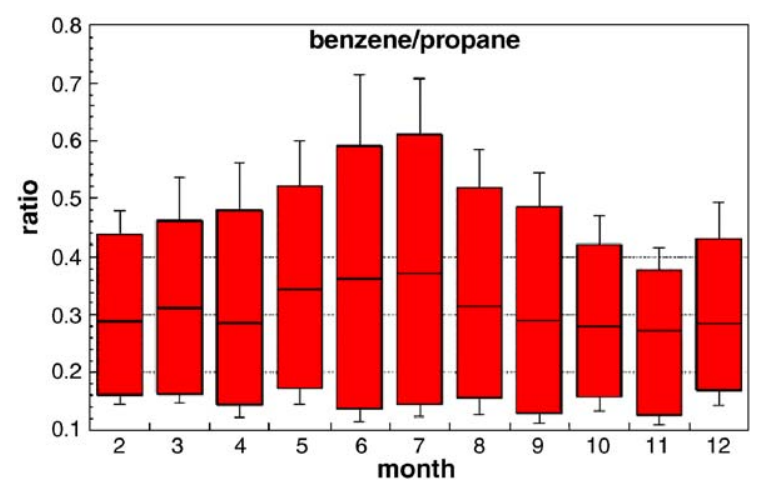

Fig. 6. Monthly distribution of ratios of benzene/propane concentrations suggesting seasonal traffic emission variability.

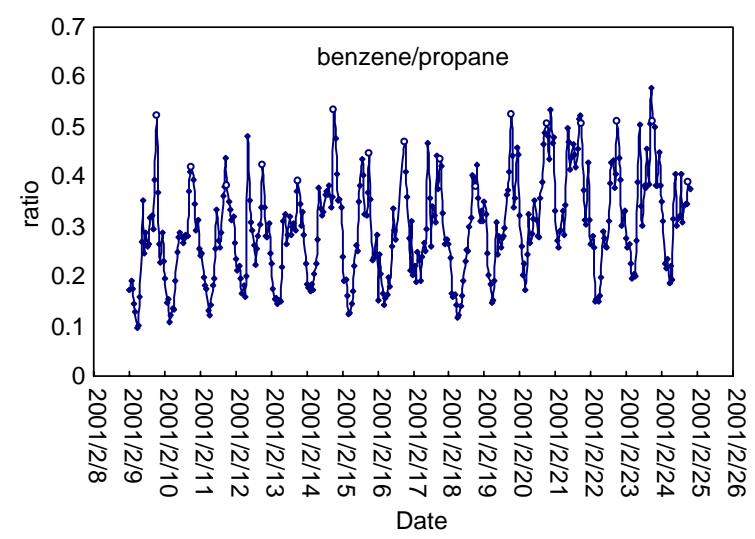

Fig. 7. Ratios of benzene to propane for the in-situ observation during February 2001. Data points at 6 PM are labeled by empty circles.

noticed and the distribution can now be recognized as emission variability. While the minimum traffic emissions remained fairly constant throughout the year, the maximum was higher in the summer than in the winter, which may have to do with the more consumption of gasoline for outdoor activities in summer months. Interestingly, by examining more closely the ratios of benzene to propane for in-situ data seen in Figs. 2(a) and (c), the diurnal cycles become more repetitive and regular than those with absolute concentrations, see Fig. 7. Almost all the peak values regularly occurred between 5 and 7 PM with 6 PM being most frequent and the lowest values occurred in the early morning before 6 AM. The morning peak values were significantly lower than the evening peak values, suggesting that evening vehicular and evaporative emissions may be stronger than morning emissions. The noon-time values were still lower than morning and evening rush hour values, but no longer as obvious as they were in absolute concentrations.
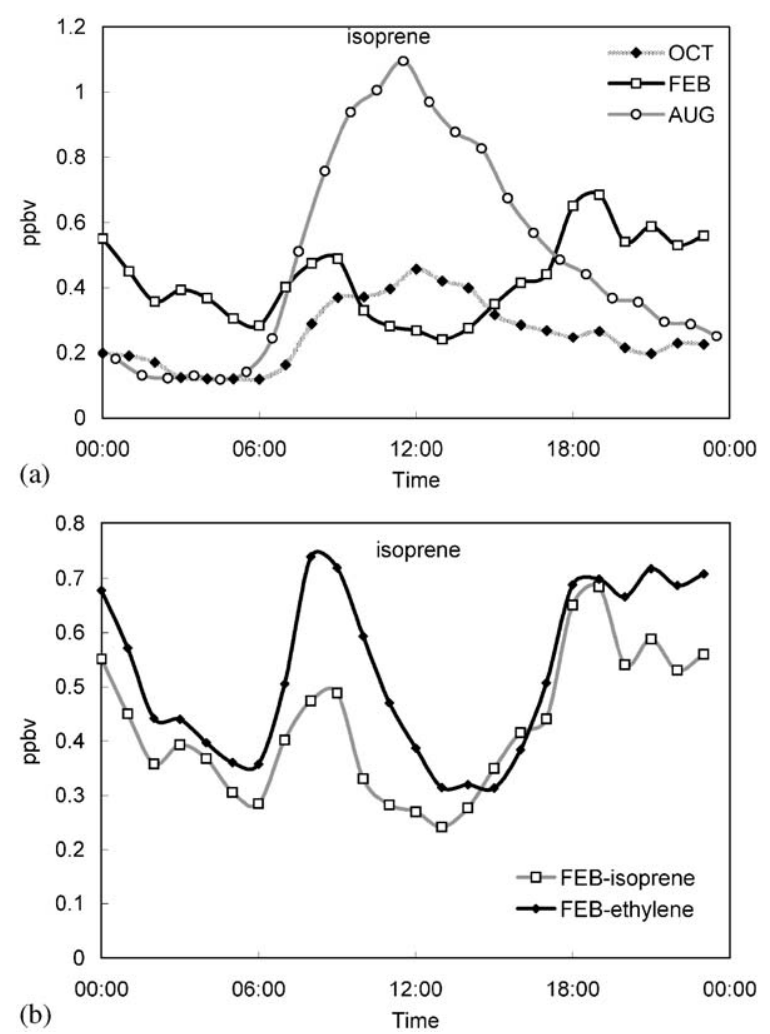

Fig. 8. (a) Hourly averaged mixing ratios of isoprene in three different months representing three seasons. Isoprene shows a unique diurnal profile in the summer with a maximum at noon as a result of intense photosynthesis activity within the plants. (b) Close resemblance between isoprene and ethylene in their wintertime diurnal profiles.

Being the most important biogenic hydrocarbon produced mainly by plants in terms of reactivity and abundance, isoprene shows a very distinct diurnal and seasonal pattern from the rest of the monitored species with little or no biogenic source, see Fig. 8. Its mixing ratios is at maximum near noon time in summer when solar radiation is most intense (see August profile in Fig. 8a), which is the opposite from the other NMHCs discussed above whose mixing ratios were at minimum during noon. Note that isoprene has an extremely short average lifetime of about $2 \mathrm{~h}$ via reaction with $\mathrm{HO}$ radicals (see Table 1), and is recognized as the single most important biogenic ozone precursor in rural areas (Ryerson et al., 2001). On a typical summer day, isoprene production is at maximum around mid-day which happens to coincide nearly in time with the noontime ozone peak, making isoprene even more decisive than most other anthropogenic NMHCs in shaping the ozone diurnal profiles, because its mid-day high concentrations will instantaneously transform part of 
isoprene into photochemical products and ozone due to its short lifetime. In winter, by contrast, the contribution to noon-time ozone peak is greatly reduced when the maximum emissions are in the morning rush hour. Although isoprene is released primarily as a by-product of photosynthesis, a small portion of isoprene is also present in vehicular exhaust (Reimann et al., 2000). This portion, however, was masked by plant production and, hence, was not revealed in our summertime measurement, but became apparent in the wintertime when the plant production subsided. In the wintertime, isoprenes diurnal profile resembles that of other tailpipe exhaust compounds, such as ethylene, having the double peak pattern (Fig. 8b). Unlike other non-biogenic species discussed earlier, whose sources have characteristic but repetitive daily features, their strong seasonality is largely the result of modulation by meteorology and chemistry. In the case of isoprene, it is the variation of source strength that dominates its diurnal or seasonal patterns. The distinct behavior of isoprene presents a unique example of how the timing of emissions and reactivity can be important in shaping the profile of a diurnal or seasonal cycle.

\section{Conclusion}

Diurnal and seasonal profiles of selected NMHCs representative of three different source types, i.e., fuel leakage, vehicular exhaust, and biogenic emissions, were identified and discussed based on the first year of an hourly monitoring program located in a metropolitan area in central Taiwan. The interplay between emission characteristics, meteorology, and chemical loss was responsible for the observed diurnal and seasonal patterns of the monitored NMHCs. For species such as ethane and propane with relatively constant source characteristics, the change in mixing height is the dominant factor modulating abundance to reveal characteristic diurnal patterns. Chemical removal is only important from the seasonal point of view, which together with temperature inversion caused the observed seasonal variations.

By referring to ethane or propane's diurnal cycles for gauging the effect induced by meteorology, the car exhaust plus evaporation type of species such as benzene showed the influence of traffic patterns superimposed on the meteorological modulation.

In the case of isoprene, a representative species for biogenic emissions, its source characteristics outweigh the effects of meteorological and chemical factors and, thus, the abundance shows entirely different diurnal and seasonal cycles which strongly reveal its source characteristics.

\section{Acknowledgements}

The authors would like to express their greatest gratitude to the Department of Environmental Monitoring and Information Management at EPA of Taiwan for their constant assistance and financial support. This research is under the contract number: EPA-92-L10502-103.

\section{References}

Blake, D.R., Rowland, F.S., 1986. Global atmospheric concentrations and source strength of ethane. Nature 321 , 231-233.

Blake, D.R., Rowland, F.S., 1995. Urban leakage of liquefied petroleum gas and its impact on Mexico City air quality. Science 269, 953-956.

Blake, N.J., Blake, D.R., Wingenter, O.W., Sive, B.C., Thornton, D.C., Bandy, A.R., Atlas, E., Flocke, F., Rowland, F.S., 1999. Aircraft measurements of latitudinal, vertical, and seasonal variations of NMHC, methyl nitrate, and selected halocarbons during the first aerosol characterization experiment (ACE-1). Journal of Geophysical Research 104, 21,803-21,817.

Chang, C.C., Lo, J.G., Wang, J.L., 2001. Assessment of reducing ozone forming potential for vehicles using liquefied petroleum gas as an alternative fuel. Atmospheric Environment 35, 6201-6621.

Chang, C.C., Lo, S.J., Lo, J.G., Wang, J.L., 2003. Analysis of methyl tert-butyl ether (MTBE) in the atmosphere and implications as an exclusive indicator of automobile exhaust. Atmospheric Environment 37, 4747-4755.

Davidson, A., 1993. Update on ozone trend in California's south coast air basin. Journal of the Air and Waste Management Association 43, 226-227.

DeLuchi, M.A., 1993. Emissions from the production, storage, and transport of crude oil and gasoline.

Dewulf, J., Langenhove, V., 1999. Anthropogenic volatile organic compounds in ambient air and natural waters: a review on recent developments of analytical methodology, performance and interpretation of field measurements. Journal of Chromatography A 843, 163-177.

EPA-454/B-93-051, 1994. PAMS Implementation Manual, March.

Grennfelt, P., Schjoldager, J., 1984. Photochemical oxidants in the troposphere: a mounting menace. Ambio 13, 61-67.

Helmig, D., 1999. Air analysis by gas chromatography. Journal of Chromatography A 843, 129-146.

http://www.iupac-kinetic.ch.cam.ac.uk/.

http://www.spectragases.com/environ/VOCgases/vocpams.htm.

Kirchstetter, T.W., Singer, B.C., Harley, R.A., 1999. Impact of California reformulated gasoline on motor vehicle emissions. 2. Volatile organic compound speciation and reactivity. Environmental Science and Technology 33, 329-336.

Koppmann, R., Johnen, F.J., Plass-Dulmer, C., Rudolph, J., 1993. Distribution of methylchloride, dichloromethane, trichloroethene and tetrachloroethene over the north and 
south Atlantic. Journal of Geophysical Research 98, $20,517-20,526$.

Maeda, T., Onodera, S., Ogino, H., 1995. On-site monitoring of volatile organic compounds as hazardous air pollutants by gas chromatography. Journal of Chromatography A 710, 51-59.

McLaren, R., Singleton, D.L., 1996. Analysis of motor vehicle sources and their contribution to ambient hydrocarbon distributions at urban sites in Toronto during the southern Ontario oxidants study. Atmospheric Environment 30, 2219-2232.

NOAA/CMDL, 2002. Summary Report, No. 26, pp. 113-114.

Novelli, P.C., Masarie, K.A., Lang, P.M., 1998. Distributions and recent changes of carbon monoxide in the lower troposphere. Journal of Geophysical Research 103, 19,015-19,033.

Oliver, K.D., Adams, J.R., Daughtrey Jr., E.H., Mclenny, W.A., Yoong, M.J., Pardee, M.A., 1996. Technique for monitoring ozone precursor hydrocarbons in air at photochemical assessment monitoring stations: sorbent preconcentration, closed-cycled cooler cryofocusing, and GC-FID analysis. Atmospheric Environment 30, 2751-2757.

Prinn, R.G., Huang, J., Weiss, R.F., Cunnold, D.M., Fraser, P.J., Simmonds, P.G., McCulloch, A., Harth, C., Salameh, P., O'Doherty, S., Wang, R.H.J., Porter, L., Miller, B.R., 2001. Evidence for substantial variations of atmospheric hydroxyl radicals in the past two decades. Science 292, 1882-1888.

Reimann, S., Calanca, Pierluigi, Hofer, P., 2000. The anthropogenic contribution to isoprene concentrations in a rural atmosphere. Atmospheric Environment 34, 109-115.

Ryerson, T.B., Trainer, M., Holloway, J.S., Parrish, D.D., Huey, L.G., Sueper, D.T., Frost, G.J., Donnelly, S.G., Schauffler, S., Atlas, E.L., Kuster, W.C., Goldan, P.D., Hubler, G., Meagher, J.F., Fehsenfeld, F.C., 2001. Observations of ozone formation in power plant plumes and implications for ozone control strategies. Science 292, 719-723.
Sagebiel, J.C., Zielinska, B., Pierson, W.R., 1996. Real-world emissions and calculated reactivities of organic species from motor vehicles. Atmospheric Environment 30, 2287-2296.

Sander, S.P., Finlayson-Pitts, B.J., Friedl, R.R., Golden, D.M., Huie, R.E., Kolb, C.E., Kurylo, M.J., Molina, M.J., Moortgat, G.K., Orkin, V.L., Ravishankara, A.R., 2002. Chemical kinetics and photochemical data for use in atmospheric studies, Evaluation Number 14, JPL Publication 02-25. Jet Propulsion Laboratory, Pasadena.

Voltz, A., Kley, D., 1988. Evaluation of the Montsouris series of ozone measurements made in the nineteenth century. Nature 332, 260-262.

Wakamatsu, S., Ohara, T., Uno, I., 1996. Recent trends in precursor concentrations and oxidant distribution in the Tokyo and Osaka areas. Atmospheric Environment 30, 715-721.

Wang, J.L., Chen, W.L., 2002. Validation of a self-developed automated system in measuring ozone precursors through inter-comparison with $\mathrm{NO}_{x}$ and $\mathrm{CO}$ instruments. Atmospheric Environment 36, 3041-3047.

Wang, J.L., Din, G.Z., 2003. Validation of a self-constructed auto-GC for the measurement of ozone precursors through inter-comparison with a commercial analogy. Journal of Chromatography A 1027, 11-18.

Wang, C.J.-L., Blake, D.R., Rowland, F.S., 1995. Seasonal variations in the atmospheric distribution of a reactive chlorine compound, tetrachloroethene $\left(\mathrm{CCl}_{2}=\mathrm{CCl}_{2}\right)$. Geophysical Research Letters 22, 1097-1100.

Wang, J.L., Ding, W.H., Chen, T.Y., 2000. Source determination of light non-methane hydrocarbons by simultaneous multi-site sampling in a metropolitan area. ChemosphereGlobal Change Science 2, 11-22.

Wang, J.L., Kuo, S.R., Ma, S.S., 2001. Construction of a low cost automated chromatographic system for the measurement of ambient methane. Analytica Chimica Acta 448, 187-193.

Wingenter, O.W., Wang, C.J.-L., Blake, D.R., Rowland, F.S., 1998. Seasonal variation of tropospheric methyl bromide concentrations: constraints on anthropogenic input. Geophysical Research Letters 25 (2), 797-2800. 